\title{
UMA ANÁLISE DE ESTRATÉGIAS DE LEITURA NO ENSINO FUNDAMENTAL I NA CIDADE DE JACINTO MACHADO
}

\author{
AN ANALYSIS OF READING STRATEGIES TEACHING IN BASIC SCHOOL IN \\ THE CITY OF JACINTO MACHADO
}

\author{
Thais Floriano de Souza ${ }^{1}$ \\ Richarles Souza de Carvalho ${ }^{2}$
}

\begin{abstract}
RESUMO: Este trabalho teve por finalidade analisar a leitura da palavra como prática social do indivíduo, entrevistando professoras do ensino fundamental I de escolas da rede municipal e estadual da cidade de Jacinto Machado, bem como as estratégias por elas utilizadas no incentivo ao hábito da leitura. A falta deste hábito pode prejudicar os alunos em seu cotidiano escolar em relação à interpretação e reflexão sobre os textos oferecidos pelas disciplinas, como também a sua qualificação para a vida profissional futura e participação em sociedade, pois um indivíduo que lê terá maior facilidade para saber agir diante dela. Utilizou-se como ferramenta de pesquisa a entrevista semiestruturada com perguntas para melhor conhecer o trabalho de cada professora em sua sala de aula. Todas as falas foram gravadas e depois transcritas para análise. A partir da pesquisa constatou-se que a prática da leitura pode ser construída através das estratégias, e estas fazem parte da maneira como a professora trabalha em sala de aula. Os alunos que leem provavelmente terão linguagem mais elaborada e melhor argumentação diante da sociedade letrada em que vive. Contudo, ao analisar os questionários, identificou-se que o ensino da leitura ainda prende-se ao tecnicismo com vistas ao mundo do trabalho e nem todos os alunos desenvolvem o hábito de leitura interpretativa.
\end{abstract}

PALAVRAS CHAVE: Leitura da palavra. Estratégias de leitura. Leitor. Inclusão social.

ABSTRACT: The purpose of this study was to analyze the reading of the word as social
practice of the individual, interviewing basic school teachers of municipal and state schools in
the city of Jacinto Machado, as well as the strategies used by them to encourage the habit of
reading The lack of this habit can harm the students in their daily school in relation to the
interpretation and reflection of texts offered in the disciplines, as well as their qualification for
future professional life and participation in society; an individual who reads will have a
greater ease in knowing how to act in society. The research tool was semi-structured interview
with subjective questions in order to better know the work of each teacher in their classrooms.
For analysis, all speeches were recorded and then transcribed. Reading pleasure can be
generated through strategies and these are part of how the teacher works in the classroom.

${ }^{1}$ Acadêmica do curso de Pedagogia da UNESC. E-mail: thais_desouza@outlook.com

2. Licenciado em Letras, doutor em Ciências da Linguagem e docente na UNESC. E-mail: rsc@ unesc.net Saberes Pedagógicos, Criciúma, v. 3, nº1, janeiro/junho 2019.- Curso de Pedagogia- UNESC 


\section{SABERES PEDAGÓGICOS}

Revista do Curso de Graduaçūo de Pedagogia - Unesc

ISSN $2526-4559$

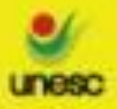

Thisuing

eduneso

Students who read will probably have more elaborated language and better argumentation in the literate society where they live. However, the answers of the questionnaires showed that teaching of reading still refers to the technicism and students develop the habit of interpretative reading.

KEYWORDS: Word Reading. Reading strategies. Reader. Social inclusion.

\section{INTRODUÇÃO}

O ensino da leitura da palavra é um dos principais compromissos da escola, fazendo com que seus alunos se tornem leitores reflexivos, contestadores, criativos, críticos e que se posicionem diante de desafios decorrentes de uma sociedade letrada (FREIRE, 1991). Esta pesquisa, fundamentada em diversos teóricos, teve como tema a leitura da palavra e como objetivo analisar como acontece o ensino da leitura em sala de aula no ensino fundamental, bem como as estratégias de leitura utilizadas pelas professoras para melhorar este processo.

A escolha desta temática surge em razão de um acontecimento em meio familiar. Há um ano, meu irmão que tinha sete anos de idade estava entrando em contato com as leituras propostas por sua professora. Porém, cada vez que ele trazia para casa o livro para suceder a leitura, não sentia prazer ou interesse em lê-lo, sequer manuseava-o com curiosidade.

A partir desta observação que fiz diante da reação dele, iniciei minhas indagações: Como a professora está trabalhando a leitura em sala de aula? As crianças reconhecem a grande importância que a leitura tem? Ainda neste diagnóstico inicial, ao conversar com alguns professores em meu local de trabalho em relação ao tema, ouvi relatos que demonstravam dificuldades em trabalhar a leitura em sala de aula.

É imprescindível ressaltar a importância de incentivar nossos alunos à leitura, e que a falta dela pode deixá-los com dificuldades de interpretação nas mais variadas atividades de sala de aula, pois os alunos que não possuem uma leitura reflexiva podem futuramente, acabar desistindo de estudar, transformando-se possivelmente em indivíduos com pouco entendimento e interação com um mundo em que a palavra escrita desempenha um papel fundamental(CARVALHO; MENDONÇA, 2006).

Assim, a realização deste trabalho procura contribuir para perceber a importância da prática pedagógica em relação ao ensino da leitura, bem como as possíveis estratégias de

Saberes Pedagógicos, Criciúma, v. 3, nº1, janeiro/junho 2019.- Curso de Pedagogia- UNESC 


\section{SABERES PEDAGÓGICOS}

Revista do Curso de Graduaçāo de Pedagogia - Unesc

ISSN $2526-4559$

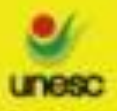

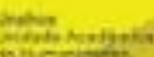

edinesc

leitura que podem ser utilizadas, viabilizando seu efetivo ensino a fim de que os alunos leiam criticamente os textos propostos, agindo como indivíduos que constroem conhecimento a partir da leitura e não apenas como leitores que procedem mecanicamente sem reflexões diante dos textos lidos.

\section{A LEITURA DA PALAVRA NO ENSINO FUNDAMENTAL}

Considerando a leitura como elemento imprescindível para a formação do cidadão, torna-se importante discutir o processo de ensino da leitura da palavra realizado por professores no ensino fundamental. Os alunos devem ser inseridos em uma condição de leitor reflexivo, crítico, sem que a leitura seja mera decodificação e atividade mecânica.

A partir do momento em que viemos ao mundo, estamos em contato constante com diferentes formas de leitura, seja ela a leitura da palavra, quando o indivíduo já consegue interpretar os códigos escritos; ou a leitura de mundo, que é todo o conhecimento construído nas mais diversas relações (FREIRE, 1991). Por isso é importante ressaltar o que Freire (1991, p. 19) nos diz: "a leitura do mundo precede a leitura da palavra", ou seja, antes mesmo de o indivíduo ler qualquer palavra, ele já possui uma leitura de mundo, um conhecimento prévio acerca de diversos assuntos/temas com os quais tem contato; é esta leitura de mundo que poderá dar início à leitura da palavra, cabe então à professora considerar este conhecimento prévio para assim iniciar o ensino. Ambas as leituras se relacionam, realidade e linguagem, assim como a leitura de mundo é importante para que se inicie a da palavra, esta também tem sua relevância, quanto mais se pratica a leitura da palavra, haverá uma tendência em desenvolver a capacidade de interpretação da realidade (FREIRE, 1991).

Conforme vamos crescendo, desenvolvemos práticas de leitura que nos fazem ter diferentes concepções sobre o mundo. Porém, estas concepções podem se alterar quando adquirimos o hábito de ler, e a partir do hábito poderá surgir o gosto pela leitura (GERALDI, 2014). Com isso, o indivíduo que lê acaba adquirindo novos argumentos para fazer suas compreensões diárias. Carvalho e Mendonça (2006, p. 21) afirmam que:

Ler com compreensão inclui [...] a capacidade de fazer inferências. A capacidade de produzir inferências diz respeito ao 'ler nas entrelinhas', compreender os subentendidos, os 'não ditos'. A

Saberes Pedagógicos, Criciúma, v. 3, nº1, janeiro/junho 2019.- Curso de Pedagogia- UNESC 


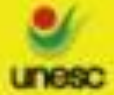

compreensão [...] depende da capacidade de construir um 'fio da meada' que unifica e inter-relaciona os conteúdos lidos, compondo um todo coerente.

Os autores Freire (1991), Geraldi (2014), Carvalho e Mendonça (2006) conceituam a leitura da palavra como uma prática importante para o ser humano, portanto, ela não pode ser entendida, nem realizada, apenas como decifração de símbolos, mas como um ato que abrange a observação atenta, a busca por novas respostas, a interpretação e também a análise e relação do que se lê. A partir do momento em que estes requisitos são explorados durante a leitura, o indivíduo acaba por favorecer sua aprendizagem e ampliar seus saberes.

Sendo assim, torna-se fundamental que o aluno crie o hábito de ler, para possivelmente sentir o prazer em desenvolver a leitura, o que lhe tornará um leitor com plena capacidade de interagir com o mundo em que vive e também consigo mesmo (GERALDI, 2014).

Ao ingressar na escola, a criança já possui um contato com a leitura da palavra, seja pelas leituras realizadas por algum membro da família, pelo contato direto que a criança tem com diversas tecnologias que proporcionam também algum tipo de leitura, enfim, a criança já possui algum conhecimento em relação a leitura da palavra, porém é na escola que o processo de ensino deve efetivar-se, de maneira que o educando use a leitura para tornar-se autônomo, construir seu próprio conhecimento, buscando estratégias para solucionar problemas, ampliando seus conhecimentos afim de pertencer e conhecer cada vez mais a realidade que vivencia. Desta forma, a escola estará cumprindo com seu papel de formar cidadãos críticos (CARVALHO; MENDONÇA, 2006).

Seguindo esse contexto de leitura na escola, Geraldi (2014, p. 91) nos diz que "a leitura é um processo de interlocução entre leitor/autor mediado pelo texto". Por isso, ao entrar em contato com o texto, o leitor precisa dialogar com o objeto de leitura e, de certa forma, com o próprio autor. Precisam estabelecer uma conversa, leitor e texto, em que o leitor não decodifica apenas, mas lê refletindo e discutindo ideias (GERALDI, 2014), e é aqui que se torna importante a escola desenvolver sua função com excelência.

A escola, quando aqui é citada, refere-se a toda comunidade escolar, que deve esforçar-se para desenvolver um ambiente propícia à leitura, auxiliando a tarefa da professora

Saberes Pedagógicos, Criciúma, v. 3, nº1, janeiro/junho 2019.- Curso de Pedagogia- UNESC 

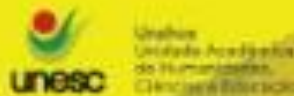

unese

em sala de aula. Nela, a leitura não deve ser apenas utilizada como um método para passar o tempo, mas, sim, de forma significativa, buscando dar ao aluno subsídios para trazer seus conhecimentos prévios para que ele possa construir relações, atribuindo significado e sentido ao que está lendo (GERALDI, 2014).

Por isso, quanto maior for o incentivo à aprendizagem da leitura da palavra, maior será a liberdade de expressão do aluno, assim como a busca para solucionar os próprios problemas, utilizando seu conhecimento de maneira significativa, ou seja, a tendência é que se torne um indivíduo com capacidade de fazer suas próprias interpretações.

Não existe uma fórmula para se ensinar a ler, o que existe é uma necessidade do indivíduo em aprender, isso porque saber ler numa sociedade que utiliza a língua escrita em praticamente todas as suas relações, é fundamental (FOUCAMBERT, 1998). Diante disso, surgem inúmeras estratégias para o ensino da leitura da palavra, principalmente nos anos iniciais do ensino fundamental; este período é, na maioria dos casos, quando os alunos iniciam seu contato diário com este tipo de leitura (FREIRE, 1991). Sendo assim, as estratégias a serem utilizadas em sala de aula terão grande influência para a formação do leitor.

\section{LER É SINÔNIMO DE INCLUSÃO SOCIAL?}

A sociedade atual é composta pelos mais diversos grupos sociais, os quais são construídos por indivíduos com formações escolares diferentes. A diferença referente somente à formação a qual esses indivíduos têm acesso acaba sendo um dos fatores que geram a exclusão. Em relação à leitura da palavra, por exemplo, quem tem o domínio do ato de ler possui melhores condições de se inserir no mercado de trabalho (FOUCAMBERT, 1998). Assim quanto melhor for a habilidade de leitura do indivíduo, tanto melhor será para que ele possa questionar seus direitos e deveres enquanto cidadão.

A capacidade de ler e a prática de leitura, conforme Britto (2012, p. 35), "tem implicações importantes na participação social dos indivíduos, contribuindo decididamente para a sua maior produtividade, intervenção política e social, organização da vida prática", 

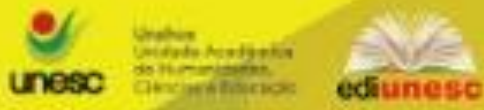

afirmando-nos, juntamente com Foucambert, que a leitura é sinônimo de inclusão social em relação a alguns compromissos a serem exercidos pelo indivíduo (BRITTO, 2012).

Sendo assim, o ser humano utiliza o seu domínio de leitura para poder participar com maior efetividade de algumas funções em sociedade. Por isso, quando o indivíduo se põe a ler, provavelmente é em razão de um compromisso, seja ele de trabalho, de estudos, enfim, de participação em alguma prática social (BRITTO, 2012).

Neste caso, conforme Britto e Foucambert, se grande parte das pessoas apenas praticam a leitura em razão de algum compromisso para a sobrevivência, como fica então a leitura espontânea, por prazer? Se a escola é o local privilegiado para se ensinar a ler, é nela que se deve incentivar as diferentes modalidades de leitura: de entretenimento, para o trabalho, leitura cotidiana etc. (BRITTO, 2012).

O indivíduo que possui o domínio da decodificação de letras e palavras já possui um requisito importante para a realização de tarefas da vida diária. Nesse caso, o ensino da leitura feito pela escola é aquele que contribui apenas para que a pessoa participe apropriadamente do cotidiano em que vive (CARVALHO; MENDONÇA, 2006). Constata-se que o indivíduo necessita da leitura para ter o emprego que almeja, bem como uma boa posição na sociedade, avançar nos estudos, porém, a leitura não deve servir apenas para se chegar a determinado nível social, mas também deve contribuir para enriquecer seus saberes e torná-lo um indivíduo mais participativo e conhecedor da realidade em que vive (CARVALHO; MENDONÇA, 2006).

\section{ESTRATÉGIAS DE LEITURA NO ENSINO FUNDAMENTAL}

A aprendizagem da leitura da palavra perpassa vários ambientes de convívio da criança, mas é na escola que essa prática deve acontecer com bastante frequência. Em uma sala de aula, existem diferenças entre os alunos, e por isso cada uma tem suas maneiras de aprender determinado conteúdo. Cabe à professora fazer um diagnóstico identificando qual seria a melhor maneira para se trabalhar em sua sala de aula, almejando assim um ensino crítico da leitura. Ao ensinar o aluno a ler, a professora está fazendo com que ele passe a

Saberes Pedagógicos, Criciúma, v. 3, nº1, janeiro/junho 2019.- Curso de Pedagogia- UNESC 

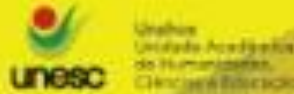

interpretar os códigos escritos, e a partir desta interpretação comece a habituar-se a ler, o que fará com que cada vez mais sua interpretação seja eficaz e assim, leitura após leitura, ele pode vir a desenvolver o gosto pelo ato de ler.

Quanto ao ensino da leitura, a professora precisa entender que existem e precisam ser utilizadas algumas estratégias, e estas devem ser ecléticas (BAMBERGUER, 1986) para que o ato de ler seja adquirido de maneira com que faça sentido às crianças. Quando falamos em estratégias de leitura, nos referimos a diferentes práticas que a professora pode desenvolver para abordar diferentes tipos de texto (CARVALHO; MENDONÇA, 2006).

Quando utilizadas com as crianças para dar início ou continuação à caminhada de leitoras, as estratégias de leitura precisam ser ainda mais motivadoras e o papel da professora neste momento é muito importante, pois será a sua prática que contribuirá para o desenvolvimento dessa capacidade nos alunos. Segundo Carvalho e Mendonça, no que diz respeito a estratégias de leitura, o professor:

\footnotetext{
a) lê em voz alta e comenta ou discute com eles os conteúdos e usos dos textos lidos; b) proporciona a eles familiaridade com os gêneros textuais diversos [...], lendo para eles em voz alta ou pedindo-lhes leitura autônoma; c) aborda as características gerais desses gêneros $[\ldots]$ e, d) instiga os alunos a prestarem atenção e explicarem os 'não ditos' do texto, a descobrirem e explicarem os porquês, a explicitarem as relações entre o texto e seu título. (CARVALHO; MENDONÇA, 2006, p. 21).
}

As estratégias de formação do leitor acabam por desenvolver no aluno uma maior familiaridade com as palavras, com a língua escrita. Para que o aluno chegue no ensino fundamental com essa familiaridade com as palavras é preciso que desde a educação infantil ele já tenha contato com os livros, ou seja, os livros devem fazer parte da sua rotina, assim como os brinquedos (PARREIRAS, 2009).

Portanto, a prática destas estratégias de leitura desde a educação infantil pode levar o aluno a criar o hábito e, por conseguinte, o gosto de ler e de perceber a importância da leitura para a sua vida, tanto pessoal quanto em sociedade (GERALDI, 2014).

$\mathrm{Na}$ escola, geralmente, os textos são lidos apenas para responder questões previamente elaboradas pela professora ou seguem as questões que já vêm prontas no livro didático, não há preocupação em levar o aluno a refletir mais profundamente sobre o texto lido; para algumas crianças a leitura torna-se algo cansativo, pois são usadas até mesmo histórias com conteúdo sem sentido como "a vaca da vovó voa". Para Lajolo (1994, p. 59), "ler não é decifrar, como

Saberes Pedagógicos, Criciúma, v. 3, nº1, janeiro/junho 2019.- Curso de Pedagogia- UNESC 

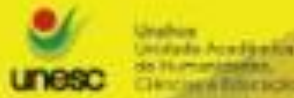

num jogo de adivinhações, o sentido de um texto. É, a partir do texto em que se procede a leitura, ser capaz de atribuir-lhe significado, conseguindo relacioná-lo a todos os outros textos significativos para cada um". Essa falta de reflexão, de entregar-se à leitura ou rebelar-se contra ela (GERALDI, 2014), acaba gerando uma falta de leitores conscientes da importância da leitura e que estão apenas atendendo as expectativas da escola (KATO, 2007).

Como consequência dessas práticas que não levam o aluno a refletir sobre o que está lendo, a leitura da palavra está ocupando um lugar cada vez menor no cotidiano das crianças. Todas essas práticas só dificultam ainda mais o caminho para que o ato de ler seja acompanhado de reflexão, interação e não por uma simples obrigação, gerando assim uma simulação de leitura (KLEIMAN, 1998) em que o aluno apenas decodifica palavra por palavra.

Cabe a nós, professoras, entendermos porque nossos alunos não sentem prazer pela leitura, sendo que alguns até leem, porém muito pouco. Kleiman conjectura (1998, p. 16), “eles [as crianças] não teriam descoberto o prazer em ler, por este motivo não leem”. Ou seja, as crianças não foram incentivadas a criar o hábito que posteriormente despertaria o prazer pela leitura. Outra possível causa para o fracasso da escola no ensino da leitura seria a própria formação de alguns "profissionais da educação que não são leitores, tendo, no entanto, que ensinar a ler e a gostar de ler.” (KLEIMAN, 1998, p. 15).

Logo, é importante indagarmos: como incorporar diferentes estratégias para a aquisição de leitura em atividades de sala de aula, sem cair no processo de simulação de leituras? Para debater essa questão, precisamos também saber como as professoras estão trabalhando a leitura em sala de aula.

\section{METODOLOGIA, APRESENTAÇÃO E ANÁLISE DE DADOS}

A pesquisa aqui desenvolvida ocorreu ao longo de um processo, sendo então qualitativa, envolvendo inúmeras fases, desde a formulação do problema, pesquisa de campo, até a relação dos resultados com as teorias até então abordadas. Gil nos diz que "pode-se definir pesquisa como o procedimento racional e sistemático que tem como objetivo 

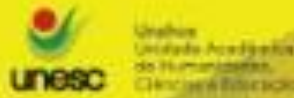

proporcionar respostas aos problemas que são propostos. A pesquisa é requerida quando não se dispõe de informação suficiente para responder ao problema." (GIL, 1996, p. 19).

No desenvolvimento deste trabalho, foi realizada uma entrevista semiestruturada com seis (06) professoras que atuam no ensino fundamental I (anos iniciais), de escolas públicas da rede estadual e municipal da cidade de Jacinto Machado-SC. Elas responderam um roteiro de perguntas no ambiente escolar ou em outro local previamente acertado. Todas as respostas foram gravadas e, depois de transcritas, analisadas a partir de alguns conceitos como: a relação entre leitura e inclusão social; as dificuldades ocasionadas a partir da dificuldade de leitura, e as diferentes estratégias de leitura que podem ser utilizadas em sala de aula no auxílio deste ensino, conceitos estes apresentados na fundamentação teórica.

No quadro abaixo encontram-se algumas informações em relação às professoras entrevistadas: a formação de cada uma, em quais turmas estão lecionando e se trabalham em escolas municipais ou estaduais:

Quadro 01:

\begin{tabular}{|l|l|l|l|}
\hline & Formação & Turma & Rede \\
\hline Professora A & Pedagogia e Gestão & $2^{\mathbf{o}}$ ano & Municipal \\
\hline Professora B & Pedagogia e Educação Especial & $2^{\mathbf{o}}$ ano & Estadual \\
\hline Professora C & Pedagogia Anos Iniciais & $4^{\mathbf{o}}$ ano & Estadual \\
\hline Professora D & Pedagogia Educação Infantil & $3^{\mathbf{o}}$ ano & Municipal \\
\hline Professora E & Pedagogia Educação Especial & $1^{\mathbf{o}}$ ano & Municipal \\
\hline Professora F & Pedagogia Anos Iniciais & $2^{\mathbf{o}}$ ano & Estadual \\
\hline
\end{tabular}

Fonte: Pesquisa da autora.

As perguntas feitas foram as seguintes:

1. Em sua opinião, ler é sinônimo de inclusão social?

2. Que problemas podem gerar as dificuldades de aprendizagem da leitura?

3. Que estratégias você utiliza para incentivar seus alunos ao ensino de leitura?

4. Com relação à leitura nos anos iniciais, o que você acha que deveria ser feito para melhorar o desempenho dos alunos neste processo?

5. Quanto à competência de leitura, assinale a alternativa que corresponde ao que a maioria de seus alunos apresenta:

A. ( ) Ainda não sabem ler (nem mesmo decodificar);

B. ( ) Leem ainda de forma decodificada;

Saberes Pedagógicos, Criciúma, v. 3, nº1, janeiro/junho 2019.- Curso de Pedagogia- UNESC 


\section{SABERES PEDAGÓGICOS}

Revista do Curso de Graduaçāo de Pedagogia - Unesc

ISSN $2526-4559$

C. ( ) Leem construindo sentido às palavras.

Ao iniciar a entrevista com as professoras, foi questionado se "ler é sinônimo de inclusão social", detectando que na opinião de todas elas, ler realmente é sinônimo de inclusão do indivíduo na sociedade, pois afirmam que a leitura está em todos os lugares. Elas ressaltam ainda que o indivíduo que lê não só terá uma melhor socialização, interpretação e se desenvolverá melhor no mundo, como também acaba enriquecendo seu vocabulário. Foucambert (1998) nos fala que este é o leitor experiente, que por meio da leitura tem acesso à grande parte dos conhecimentos gerados pela humanidade, desenvolve a sua visão de mundo, a compreensão, a comunicação e também o senso crítico (FOUCAMBERT, 1998). A leitura, portanto, leva o indivíduo a viver sua cidadania com clareza, transformando a si e toda a realidade que o cerca.

Em uma das falas, mais precisamente da professora $\mathrm{A}$, há a afirmação de que o indivíduo que lê conseguirá um “emprego com remuneração melhor”. Essa ideia nos remete ao ensino da leitura da palavra feito pela escola que continua contribuindo somente para que a pessoa participe do cotidiano em que vive e não para desenvolver atitudes críticas, contestadoras em relação ao mundo (CARVALHO; MENDONÇA, 2006) pois, a palavra escrita ainda é considerada uma grande ferramenta para que se compreenda a sociedade, podendo dar ao indivíduo a capacidade de interpretá-la.

Em sequência, foram debatidos quais problemas os alunos poderiam ter em relação à dificuldade de aprendizagem da leitura. Todas foram unânimes em afirmar que a não leitura ou a dificuldade de exercê-la traz implicações ao aluno quanto a sua interpretação diante de textos. Como consequência ele começa a sentir-se excluído, gerando dificuldades de aprendizagem em todas as disciplinas e não somente na disciplina de Português, iniciando um processo de timidez ao ler, tornando-se indiferente perante as atividades em sala.

Relacionando as respostas das professoras com os autores lidos, destaca-se que a leitura precisa ser trabalhada em todas as disciplinas dentro de uma concepção interdisciplinar, ou seja, sem ser uma prática isolada dos demais conhecimentos, para assim desenvolver um leitor experiente (KLEIMAN, 1998), que articule os conhecimentos, tenha objetivo ao ler e consiga compreender o que está lendo.

Saberes Pedagógicos, Criciúma, v. 3, nº1, janeiro/junho 2019.- Curso de Pedagogia- UNESC 
Quanto ao desenvolvimento da leitura, este é um processo que acontece de maneira diferente em cada indivíduo, por isso o incentivo deve ser constante, pois alguns podem ter mais dificuldades para conseguir decodificar e interpretar a palavra e assim podem sentir-se excluídos em relação aos demais. É aqui que aparecem as dificuldades de aprendizagem, pois quem não lê ou lê com dificuldade, acaba não interpretando e, independente da disciplina, todas precisam interpretar. Sendo assim, aprender a ler, refletindo sobre o texto, torna-se fundamental para que o indivíduo use desta leitura para conhecer melhor a sua realidade conheça e possa integrar-se de maneira mais efetiva a ela, pois o ato de ler abre novas perspectivas, novos argumentos, permitindo-lhe posicionar-se criticamente diante da realidade (ZILBERMAN, 1982).

A pergunta foi sobre quais eram as estratégias utilizadas pelas professoras para incentivar o hábito de leitura nos seus alunos, pois o uso de estratégias adequadas pode estimular este hábito, fazendo com que ele se torne um costume, o que, segundo Britto (2012, p. 47), acaba construindo uma leitura frequente que "permite situações positivas de ampliação da subjetividade e da capacidade de agir com propriedade na sociedade".

Considerando as respostas, verificou-se que as professoras A, C, D, E e F utilizam estratégias de leitura em que os alunos compartilham com a turma as histórias que estão lendo. O que cada criança conta de sua leitura é considerado, pois é a leitura que elas desenvolveram, e "também gera bastante discussão em relação como cada um entendeu" (Professora C). Além disso, as professoras trabalham histórias que demonstram a realidade; leem em voz alta para que os alunos percebam a entonação de voz; trabalham em sala de aula diferentes tipos de textos e a produção e interpretação de imagens e tirinhas, em que cada um faz a sua história e depois socializa com a turma.

Geraldi (2014) concorda com o que foi afirmado pelas professoras ao escrever que os alunos, ao compartilharem suas leituras, além de perceberem e analisarem a leitura que o outro fez em relação a determinado texto, podem também se interessar por essa outra leitura Ao trabalhar com diferentes textos, os alunos acabam conhecendo-os, e o interesse por eles, ou seja, por essas leituras de diferentes gêneros pode ser construída, sendo esta uma maneira de estabelecer a relação entre o leitor e o ouvinte e o interesse pelo conteúdo (BAMBERGER, 1986). O leitor, durante o ensino fundamental $I$, tem a chance de ser somente um 


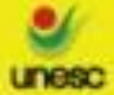

decodificador da palavra ou pode conhecer o que realmente é a leitura interpretativa que proporciona autonomia, transformação e ampliação de conhecimentos.

É importante também trabalhar utilizando textos reais (GERALDI, 2014), autênticos, pois são estes que fazem parte do cotidiano. Ainda para que o interesse pela leitura seja real, a professora pode trazer para a sala de aula textos com assuntos polêmicos, algo que incentive a curiosidade de seus alunos para assim procederem a leitura. Se assim for realizado, talvez o leitor terá uma razão ao ler, terá um objetivo, um propósito estabelecido pelo professor, e essa sim será uma leitura significativa. Porém, quando forem utilizados textos apenas para responder questões que os acompanham, sem criticidade, esta será uma leitura mecânica, sem finalidade, que estará apenas "atendendo as expectativas da escola." (KATO, 2007, p. 134).

Para a professora E, que está com turma de alunos ainda não alfabetizados, a utilização da leitura através do lúdico leva em consideração que a criança nos primeiros anos do ensino fundamental ainda tem bastante desejo para brincar, assim a professora procura não dar ênfase aos exercícios repetitivos quando trabalha a habilidade de leitura (BAMBERGER, 1986). Quando ela deixa seus alunos "manusearem os livros, criarem histórias orais a partir das imagens, prestarem atenção na entonação de voz, eles dialogam sobre isso" (professora E), o que faz com que esses alunos sintam o interesse em aprender a ler, em querer descobrir o que cada palavra significa. Parreiras (2009) ressalta a importância de trabalhar com livros desde a educação infantil, pois estes devem participar do cotidiano da criança junto aos brinquedos para que se tornem parte da rotina e assim possivelmente sejam desejados pelas crianças.

$\mathrm{Na}$ fala da professora $\mathrm{B}$, houve a ausência das palavras LIVRO, LER e LEITURA, o que remete ao pensamento de Zilberman, em que a escola pode cumprir seu papel de incentivar o hábito de leitura, transformando então o indivíduo habilitado à leitura em um leitor ou não, o que pode também reverter no seu contrário, nesse caso, a criança pode afastarse de qualquer tipo leitura, mas, sobretudo dos livros (ZILBERMAN, 1982). Por isso a importância de os livros serem utilizados em sala de aula, de ler para os alunos a fim de incentivá-los ao hábito da leitura. Assim como o brinquedo que é entregue à criança desde cedo, o livro também pode e deve fazer parte deste cotidiano.

Para dar continuidade às entrevistas, foi levantada a seguinte questão às professoras: Com relação à leitura nos anos iniciais, o que você acha que deveria ser feito para melhorar o

Saberes Pedagógicos, Criciúma, v. 3, nº1, janeiro/junho 2019.- Curso de Pedagogia- UNESC 


\section{SABERES PEDAGÓGICOS}

Revista do Curso de Graduaçāo de Pedagogia - Unesc

ISSN $2526-4559$

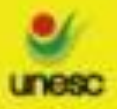

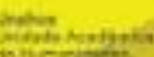

desempenho dos alunos neste processo? As respostas de todas as professoras relacionaram-se entre si, pois trouxeram informações como: trabalhar mais com seus alunos a hora do conto, iniciar pela leitura de imagens para chegar à leitura da palavra, trabalhar com a entonação de voz durante a leitura para seus alunos e incentivá-los à produzir textos orais ou escritos a partir do que leram, além de "cobrar bastante a leitura deles" (Professoras B, C e D).

Analisando as respostas iniciais desta questão, verificou-se que é necessário trabalhar conforme as professoras relatam, trazer a imagem para incentivar a leitura, ler pausadamente para que ouçam como realmente é pronunciada cada palavra, porém não ler de maneira fragmentada, e claro, incentivar a produção escrita e até mesmo oral, assim também estarão habituando-se à leitura.

Contar e ler histórias em voz alta e falar sobre livros e gravuras é importantíssimo para o desenvolvimento do vocabulário, do conhecimento, e mais importante ainda para a motivação da leitura. Sendo assim, torna-se importante desenvolver a leitura da palavra, pois isso implica em uma visão crítica, de interpretação e de questionamento do que foi lido (FREIRE, 1991).

Quanto à fala das professoras B, C e D: "Cobrar bastante a leitura deles", Geraldi (2014, p. 61) adversa, dizendo que "o professor não deve visar à cobrança da leitura, dado que o que se busca é desenvolver o gosto pela leitura”. Sendo assim, o papel da professora não é de exigir que seus alunos leiam exaustivamente em grandes quantidades, pois esta quantidade pode tornar se converter em uma leitura mecânica, quando o aluno pode apresentar, sim, resumos do que leu, porém sem entendimento, compreensão, exercendo uma leitura sem o gosto (GERALDI, 2014).

Finalizando as entrevistas, foi questionado qual seria a competência de leitura da maioria dos seus alunos, ou seja, saber como realmente está o desenvolvimento da leitura deles para assim entender se as estratégias anteriormente relatadas pelas professoras condizem com a necessidade de seus alunos.

As professoras A, B, C, D e F afirmaram que a maior parte dos alunos de sua turma já sabem ler construindo sentido às palavras. Contudo, a professora $\mathrm{E}$, que ainda está com seus alunos em processo de alfabetização, respondeu que eles ainda não sabem ler.

Comparando as estratégias por elas utilizadas com a competência de leitura dos

Saberes Pedagógicos, Criciúma, v. 3, nº1, janeiro/junho 2019.- Curso de Pedagogia- UNESC 

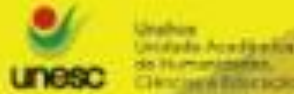

alunos, as professoras realmente estão trabalhando com estratégias adequadas para que continuem a desenvolver o ato de ler e acabem construindo o hábito de leitura. É importante lembrar que a cobrança excessiva de leituras pode fazer com o aluno acabe não construindo o hábito de ler, e isso não lhe fará ter gosto pela leitura (GERALDI, 2014).

Portanto, torna-se necessário utilizar leituras que estejam adequadas à competência de leitura em relação a cada turma, pois Bamberger (1986, p. 22) afirma que "Ninguém gosta de fazer coisas em que encontra muita dificuldade, por isso o professor precisa promover a prontidão para a leitura em todos os níveis de escolaridade", adequando as leituras a seus alunos, enfim, ensinando realmente a ler, lendo para seus alunos, dando as entonações de voz necessárias, pois “as crianças não leem por que não sabem ler direito.” (BAMBERGER, 1986, p. 24). Dessa forma torna-se imprescindível, segundo Geraldi (2014, p. 110), "resgatar na escola e trazer para dentro dela o que dela se exclui por princípio: o prazer de ler sem ter que apresentar ao professor e à escola o resultado desse prazer, que é a própria leitura”.

\section{CONCLUSÃO}

O trabalho realizado teve como tema a leitura da palavra no ensino fundamental I, tendo como objetivo analisar como acontece este ensino em sala de aula, bem como as estratégias de leitura utilizadas pelas professoras para melhorar este processo.

Desse modo, a partir das respostas, verificou-se que a prática de leitura ensinada pela escola ainda está vinculada principalmente ao trabalho, ou seja, a leitura é ensinada para que o indivíduo seja capaz de ter uma maior competitividade no mercado de trabalho, sem que de fato haja uma promoção de um leitor o qual possa encarar o mundo de maneira crítica, inclusive intervindo em sociedade. Assim como relatado pelas professoras, ler é sinônimo de inclusão social, em que o indivíduo que lê terá maneiras mais diversificadas de resolver seus conflitos bem como um uma melhor busca por trabalho, porém volto a destacar a importância de que a leitura não pode remeter-se somente para a questão de emprego.

A leitura que é necessária para o indivíduo pode ser construída através do hábito de ler, e este hábito deve surgir através de estratégias. As estratégias devem estar adequadas à competência de leitura de cada turma, e para isso a professora precisa planejar suas aulas de

Saberes Pedagógicos, Criciúma, v. 3, nº1, janeiro/junho 2019.- Curso de Pedagogia- UNESC 


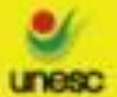

acordo com as necessidades dos alunos e não apenas como a professora imagina trabalhar. Trabalhando diariamente com diferentes textos, o aluno passará a habituar-se a ler, por isso a importância do uso de livros de diferentes gêneros textuais em sala de aula desde a educação infantil.

Independentemente da idade e da escolaridade, a professora precisa respeitar as particularidades de seus alunos para que estes não se sintam diferentes quanto ao seu desenvolvimento de leitura. Podendo também sentirem-se excluídos dos demais, gerando dificuldades de aprendizagem, timidez ao procederem a leitura, entre outros problemas. Assim, torna-se importante a professora motivar os alunos a ler, pois estes poderão ter um melhor posicionamento diante da sociedade, ampliar seus conhecimentos e nada melhor do que a própria professora ser um exemplo de leitora.

Destaca-se que a leitura precisa ser trabalhada em todas as disciplinas sem estar restrita somente ao Português, sendo evidente que todas as aulas precisam do ato de ler. Com isso, a escola pode e deve cumprir seu papel que é fazer com que seus alunos habituem-se à leitura e que não se afastem dos livros, pois estes devem fazer parte do cotidiano dos alunos.

Este trabalho abordou reflexões a respeito da prática pedagógica para que se construa com os alunos uma leitura reflexiva e não de mera decodificação da palavra. Sendo assim, é necessário repensar as estratégias de leitura em sala de aula para que se alcancem os verdadeiros sentidos da leitura da palavra.

\section{REFERÊNCIAS}

BAMBERGER, Richard. Como incentivar o hábito de leitura. 2. ed. Trad. Octavio Mendes Cajado. São Paulo: Ática, 1986.

BRITTO, Luiz Percival Leme. Inquietudes e desacordos: a leitura além do óbvio. Campinas: Mercado de Letras, 2012.

CARVALHO, Maria Angélica Freire de; MENDONÇA, Rosa Helena. Práticas de leitura e escrita. Brasília, DF: Ministério da Educação, 2006.

FOUCAMBERT, Jean. A criança, o professor e a leitura. Trad. Marlene Cohen, Carlos Mendes Rosa. Porto Alegre: Artmed, 1998. 
FREIRE, Paulo. A importância do ato de ler: em três artigos que se completam. 25. ed. São Paulo: Ed. Cortez, 1991.

GERALDI, João Wanderley. Prática da leitura na escola. In: GERALDI, João Wanderley (Org.). O texto na sala de aula. 1. ed. São Paulo: Anglo, 2014.

GIL, Antônio Carlos. Como elaborar projetos de pesquisa. 3. ed. São Paulo: Atlas, 1996. KATO, Mary Aizawa. O aprendizado da leitura. 6. ed. São Paulo: Martins Fontes, 2007. KLEIMAN, Ângela. Oficina de leitura: teoria \& prática. 8. ed. Campinas, SP: Pontes, 1998. LAJOLO, Marisa. Do mundo da leitura para a leitura do mundo. 2. ed. São Paulo: Ed. Ática, 1994.

PARREIRAS, Ninfa de Freitas. Confusão de línguas na literatura: o que o adulto escreve, a criança lê. Belo Horizonte: RHJ, 2009.

ZILBERMAN, Regina. A leitura na escola. In: AGUIAR, Vera Teixeira de; Leitura em crise na escola: as alternativas do professor. Porto Alegre: Mercado Aberto, 1982. 